\title{
Influence of fuel type, dilution and equivalence ratio on the emission reduction from the auto-ignition in an Homogeneous Charge Compression Ignition engine
}

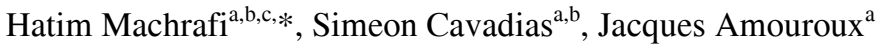 \\ ${ }^{a}$ UPMC Université Paris 06, ENSCP, 11, rue de Pierre et Marie Curie, 75005 Paris, France \\ bUPMC Université Paris 06, Institut Jean Le Rond D’Alembert, 4, place Jussieu, 75252 Paris cedex 05, France \\ ${ }^{\mathrm{c}}$ Université Libre de Bruxelles, TIPs - Fluid Physics, CP165/67, 50, Avenue F.D. Roosevelt, 1050 Brussels, Belgium \\ *Corresponding author. Tel.: +331442767 18; Fax: +33143265813
}

\begin{abstract}
One technology that seems to be promising for automobile pollution reduction is the Homogeneous Charge Compression Ignition. This technology still faces auto-ignition and emission control problems. This paper focuses on the emission problem, since it is incumbent to realize engines that pollute less. For this purpose, this paper presents results concerning the measurement of the emissions of $\mathrm{CO}, \mathrm{NO}_{\mathrm{x}}, \mathrm{CO}_{2}, \mathrm{O}_{2}$ and hydrocarbons. HCCI conditions are used, with equivalence ratios between 0.26 and 0.54 , inlet temperatures of $70{ }^{\circ} \mathrm{C}$ and $120{ }^{\circ} \mathrm{C}$ and compression ratios of 10.2 and 13.5, with different fuel types: gasoline, gasoline surrogate, diesel, diesel surrogate and mixtures of nheptane/toluene. The effect of dilution is considered for gasoline, while the effect of the equivalence ratio is considered for all the fuels. No significant amount of $\mathrm{NO}_{\mathrm{x}}$ has been measured. It appeared that the $\mathrm{CO}, \mathrm{O}_{2}$ and hydrocarbon emissions were reduced by decreasing the toluene content of the fuel and by decreasing the dilution. The opposite holds for $\mathrm{CO}_{2}$. The reduction of the hydrocarbon emission appears to compete with the reduction of the $\mathrm{CO}_{2}$ emission. Diesel seemed to produce less $\mathrm{CO}$ and hydrocarbons than gasoline when auto-ignited. An example of emission reduction control is presented in this paper.
\end{abstract}

Key words: HCCI emission-control, gasoline, diesel, dilution, toluene

\section{Introduction}

The increasing use of automobiles (Diesel Compression Ignition and Gasoline Spark Ignition) put the environment in front of great challenges. To decrease the pollution, several restrictions are imposed. Meeting these restrictions would imply finding alternative means for transportation. Ideally, such an alternative should not be dependent on *Corresponding author: Fax: +33 1432658 13. E-mail: $\underline{\text { hatim-machrafi@enscp.fr }}$ 
fossil fuels, emit no harmful products and have a better efficiency. It is unrealistic to believe that a substantial portion of the fossil fuel used for vehicle propulsion could be replaced by sustainable alternatives in the nearby future, having better efficiencies [1]. Therefore it can be said that the use of IC engines will most likely continue for a while and that, as long as no outstanding alternative is available, research that focuses on improving the internal combustion engine concept is justified. A very promising alternative combustion seems to be: The Homogeneous Charge Compression Ignition (HCCI). HCCI can be defined as a premixed, lean burn combustion process. The HCCI engine generally runs on a lean, diluted mixture of fuel, air and combustion products, which is not ignited by a spark but by compression auto-ignition instead. Auto-ignition is said to occur simultaneously at many locations, called hot spots, throughout the cylinder. Furthermore, it is claimed that turbulence is of minor importance for the combustion process, though more research is needed in this domain. It is generally agreed upon that the HCCI process is mainly driven by chemistry and much research has been performed, studying chemical interaction during auto-ignition for the fuels that are used in this work. Just to mention a few: n-heptane/toluene mixtures [2], gasoline and its surrogate [3] and diesel and its surrogate [4]. While SI engines are characterized by a low efficiency at part load and Diesel engines by high emissions of particulate matter and $\mathrm{NO}_{\mathrm{x}}$, the $\mathrm{HCCI}$ engine has neither of these problems: as the peak temperature in the cylinder is low for lean, diluted mixtures, $\mathrm{NO}_{\mathrm{x}}$ concentrations are reported [5] to be two orders of magnitude lower than for the SI and Diesel engines, whereas the particulate emissions are negligible.

Researchers [6,7] have been able to run stable HCCI combustion with conventional fuels such as gasoline, which is along with diesel, mostly used for terrestrial transport nowadays. Some work has even shown the feasibility of running HCCI combustion in a gasoline engine at different speeds, though not much higher than $2000 \mathrm{rpm}$, attaining an indicated mean effective pressure (IMEP) of 6.8 bar and ultra-low $\mathrm{NO}_{\mathrm{x}}$ emissions [8]. Also diesel engines have been modified in order to operate in HCCI mode. In, for instance, [9], it has been shown that, indeed, ultra-low emissions of $\mathrm{NO}_{\mathrm{x}}$ have been attained, when investigating the influence of Exhaust Gas Recirculation (EGR) on the auto-ignition process and comparing it, this time, to the results from a diesel engine. Also, the equivalence ratio appeared to have a direct influence. This suggests that EGR and the equivalence ratio could be interesting control parameters for the auto-ignition. However, higher $\mathrm{CO}$ and hydrocarbon emissions were attained than in the case of the diesel engine. 
These results summarize the problem that is of interest in this paper and that is to be resolved. One of the control parameters mentioned is EGR. EGR has different effects: dilution, thermal and chemical effects are the most important ones. As is mentioned in [9] and [10], investigating the precise effect of EGR is not that evident and in most experimental investigations the effect of EGR is only considered as a whole. It is therefore, for understanding reasons, interesting to consider each effect separately. Considering the thermal effect of EGR is the same as considering the effect of the inlet temperature, from a theoretical point of view. Since these experiments can easily be found in the literature, having an effect that is already reasonably well known, this is not treated in this paper. Before the chemical effect can be studied thoroughly, the effect of dilution must be well comprehended and therefore this effect is considered in this paper. The effect of dilution can be divided in two parts: the influence on initial concentration of the reactants and the influence on the heat capacity, which is indirectly related to the thermal effect. In order to exclude any thermal effect, only the influence on the initial concentration of the reactants by dilution is considered, choosing nitrogen, since its heat capacity is not much different from that of air. The equivalence ratio being a strong control parameter [11,12], influences not only emissions but also engine performances and is also considered in this paper.

As has been said before, the high emissions of $\mathrm{CO}$ and hydrocarbons are still a problem $[13,14]$ and exhibit higher emissions than a conventional diesel engine. Moreover, increasing the EGR rate, which is used for controlling purposes, increases the emission of CO [14]. The same goes for the hydrocarbon emissions [15]. This increase in emission can be countered by adding at the same time another controlling parameter. In most of the times, results concerning the influence of dilution, equivalence ratio and fuel type on the emissions in an HCCI engine are presented one at the time. In order to control the emissions, it can be useful to present the influence of two control parameters at the same time, followed by a controlling strategy. This controlling strategy should be preceded by a comparison of different fuels as well. This papers aims, therefore, to investigate two subjects. The first is the effect of the dilution, fuel type and equivalence ratio on the emissions of $\mathrm{CO}, \mathrm{NO}_{\mathrm{x}}, \mathrm{O}_{2}, \mathrm{CO}_{2}$ and the total hydrocarbons in an HCCI engine. The second is an outline for a controlling strategy of the emissions. The fuels that are used are gasoline, diesel, Toluene Reference Fuels (TRF) and surrogates of gasoline and diesel. The operating conditions concerning the inlet temperature, equivalence ratio and compression ratio will be presented at the corresponding discussions. 


\section{Experimental System}

\subsection{Engine and experimental set-up}

The engine used in this work is a water-cooled mono-cylinder Research engine modified for operation in HCCI mode at a constant engine speed of $600 \mathrm{rpm}$. As has been said before, turbulence is claimed to be of minor importance during HCCI combustion. Since this is not totally agreed upon, in order to limit its influence, which allows studying the effects of the control parameters with as less perturbation as possible, a low engine speed is chosen. The lowest engine speed available on this type of engine is $600 \mathrm{rpm}$. The experimental set-up can be seen in figure 1 . Table 1 presents the characteristics of this engine. The modifications included the injections system, the EGR system and the equipment for measurement. The injection system concerned a High Pressure Liquid Chromatography (HPLC) pump, which regulates the fuel rate and pumps it into a pre-mixture tank via a nebulizer assisted with 3 bar injection pressure. Into this pre-mixture tank, air is introduced at a fixed rate. The inlet temperature (just before the intake valve) and inlet pressure (pre-mixture tank) are also regulated via sensors that are related to the control unit. These fixed rates determine the equivalence ratio. The EGR (dilution by nitrogen in the case of this paper) flow is maintained by a flow meter and nitrogen is then introduced in the pre-mixture tank. The dilution $(\mathrm{D})$ is then defined by volumetric flow rates $(\mathrm{F})$ as:

$D=\frac{F_{\text {nitrogen }}}{F_{\text {fuel / air }}+F_{\text {nitrogen }}}$

The measurement equipment concerns different sensors that were placed in the whole set-up: in the engine to monitor the pressure, the pressure of injection, the inlet and exhaust temperature, the mass flows of the fuel, the air and the diluents (nitrogen).

Table 2 presents the experimental test conditions. During the experiments, the oil temperature is set at $40{ }^{\circ} \mathrm{C}$ and the cooling water temperature at $50{ }^{\circ} \mathrm{C}$. The gas to be analysed is taken directly from the beginning of the exhaust pipe and pushed by the exhaust stroke towards a COSMA analyser. The measurements were repeated three times at the same operating conditions. The gas analysis is performed by using a COSMA analyser. The following gasses were analysed, with each gas having its analyser:

- CO, analysed by Cosma Beryl 100, IR

- $\mathrm{CO}_{2}$, analysed by Cosma Beryl 100, IR 
- $\quad \mathrm{NO}_{\mathrm{x}}$, analysed by Cosma Topaze 3010, Chemiluminescence

- HC, analysed by Cosma Graphite 55, FID

The measurement of $\mathrm{CO}$ and $\mathrm{CO}_{2}$ takes place by absorption of infra-red radiation and is given in volumetric percentage. The $\mathrm{NO}_{\mathrm{x}}$ analyser functioning is based on chemiluminescence, giving the amounts in ppmv. To measure the HC quantity leaving the engine, the method of FID (Flame Ionisation Detector) is used, showing values in ppmv. More information about the principles of infra-red absorption techniques, chemilumineschence and FID methods one can consult respectively [16], [17] and [18].

\subsection{Experimental apparatus and accuracy}

Since the HCCI conditions are nowadays not specified exactly, but rather operating ranges are given instead, the experiments with the HCCI engine are performed in a certain range of control parameters. These parameters exhibit a certain uncertainty range. The measurements and calculated parameters also have certain accuracy. The measurements concern the fuel flow, air flow, EGR flow, temperature of the inlet mixture and EGR, injection (into the pre-mixture tank) pressure (which is a pressure relative to the atmospheric pressure), cylinder pressure and the emissions of the species $\mathrm{CO}, \mathrm{CO}_{2}, \mathrm{NO}_{\mathrm{x}}$ and hydrocarbons. The accuracies of these measurements are given in Table 3 , including the values for oxygen as well.

From these control parameters, some calculated control parameters can be obtained, such as the dilution, the equivalence ratio and the compression ratio. Using the principle of root-mean square method [19], the accuracies of these parameters are found to be $0.5 \%$ for the dilution rate, $+/-0.005$ for the equivalence ratio and $+/-0.5$ for the compression ratio (which is calculated by means of the pressure measurement in the engine). Since aromatics are major polluters in conventional fuels, the emissions of mixtures of n-heptane and toluene are also studied as a function of the equivalence ratio. The toluene percentage goes up to $40 \mathrm{vol} \%(+/-1 \mathrm{vol} \%)$.

\subsection{Performance runs}

It is important to characterize the performance of the engine with respect to its indicated efficiency and indicated mean effective pressure in order to put the emissions in perspective. This is done as a function of the equivalence ratio, since most of the results in this paper are measured for different equivalence ratios. Figure 2 presents the indicated efficiency as a function of the equivalence ratio for the fuels TRF24 (24 vol\% toluene and 76 vol\% n- 
heptane) and gasoline. These fuels are chosen for these performance runs, since most of the experiments in this papers are performed with these fuels. The experiments are performed with an inlet temperature of $70{ }^{\circ} \mathrm{C}$ and a compression ratio of 10.2. The value for the inlet temperature (higher than the ambient temperature) is chosen in order to facilitate combustion. Otherwise, high equivalence ratios (more fuel consumption) or compression ratios would be required which increase the risk of engine damage. As can be seen from figure 2, the maximum indicated efficiencies are between 35 and $38 \%$, which is quite acceptable comparing it to conventional diesel engines. Figure 3 shows the same as figure 2 for the and the indicated mean effective pressure (IIMEP). The IMEP, depending on the equivalence ratio, at the maximum indicated efficiency are between 3 and 4 bar, depending on the fuel.

\section{Results and discussion}

This paragraph presents the results concerning the $\mathrm{CO}, \mathrm{CO}_{2}, \mathrm{O}_{2}$ and hydrocarbon emissions that are measured in the HCCI engine. The results of the $\mathrm{NO}_{\mathrm{x}}$ emissions are not presented, since no $\mathrm{NO}_{\mathrm{x}}$ (detection limit of 10 ppmv) is observed for the whole investigated range. This result is satisfactorily confirmed by other work. Depending on the engine speed and torque and using EGR, in [8] it is found that $\mathrm{NO}_{\mathrm{x}}$ emissions between 10 and 30 ppm for HCCI diesel combustion. In other work [14] $\mathrm{NO}_{\mathrm{x}}$ emission values were found going from 130 ppm to near-zero $\mathrm{NO}_{\mathrm{x}}$ emissions depending on the EGR rate and fuel quantity per cycle, also for HCCI diesel combustion. For HCCI gasoline combustion, also near-zero $\mathrm{NO}_{\mathrm{x}}$ emissions were found [20]. It appeared that for having the ultra-low $\mathrm{NO}_{\mathrm{x}}$ emissions, HCCI combustion is a good alternative, though relatively low fuel quantities should be used and if not, this should be compensated by high EGR rates. In the whole experimental range in this work it appeared that no $\mathrm{NO}_{\mathrm{x}}$ emission has been detected. This already implies an important feature of the HCCI engine, being the low $\mathrm{NO}_{\mathrm{x}}$ emission. The majority of the results are presented in the form of contour maps, where a certain emission is presented as a function of two parameters. This means that a certain emission is measured at a certain equivalence ratio whilst changing for instance the dilution by EGR. The same series of experiments is then repeated for several equivalence ratios. The obtained results are then summarized in a contour map. This has the advantages that a detailed wide range of work can be presented without too many figures and that an overall idea can be obtained of the behaviour of a certain emission $\left(\mathrm{CO}_{2}\right.$, for instance) as a function of two parameters. Gasoline and diesel are conventional fuels and before other more interesting fuels can be investigated, such as biofuels, it is of importance to document important results containing the emission of conventional fuels. Surrogates of gasoline and diesel are also 
shown, since the real conventional fuels contain dozens and dozens of components, making their modeling by chemical kinetics cumbersome. The gasoline surrogate contains 11 vol\% n-heptane, 59 vol\% iso-octane and 30 vol $\%$ toluene [3] and the diesel surrogate contains 76 vol\% n-heptane and 24 vol\% toluene [4].

\subsection{Emissions from the HCCI engine with gasoline and its surrogate}

This section presents the emissions that are measured in the HCCI engine concerning gasoline and its surrogate (11 vol\% n-heptane, 59 vol\% iso-octane and 30 vol\% toluene). Figures 4 to 7 show the emissions as a function of the dilution by $\mathrm{N}_{2}$ and the equivalence ratio, using gasoline as the fuel. Since EGR dilution is expected to take part of the control of the HCCI auto-ignition, it is worth finding out how much the dilution influences these emissions. Figures 8 to 11 present the same for the gasoline surrogate.

First of all, it can be said that the emissions of gasoline and those of the surrogate show qualitatively the same trends and quantitatively the differences are acceptable with the exception of the hydrocarbon emissions at high equivalence ratios. It could be that at low equivalence ratios, the difference between gasoline and its surrogate are not visible and that this difference is clearer when more fuel is injected. Figures 4 to 11 show that the dilution increases the emission of hydrocarbons and $\mathrm{CO}$, while it decreases that of $\mathrm{CO}_{2}$ and $\mathrm{O}_{2}$. This trend is found in the literature and is generally agreed upon [21,22].

It is clear that the dilution influences strongly the emissions of $\mathrm{CO}_{2}$ and the hydrocarbons, while the emission of $\mathrm{CO}$ changes less pronouncedly. Looking to the contour lines of oxygen it seems that the dilution influences strongly the oxygen content in the exhaust as well. Since, at higher dilutions, fewer hydrocarbons are present due to a reduced reactivity, less oxygen has reacted with the fuel and thus more oxygen should be present in the exhaust. The opposite is observed, however, which confirms the strong effect of dilution. This effect causes a lower oxygen concentration, which decreases the probability of the oxygen molecules to collide with the fuel. Moreover, the dilution lowers the overall concentrations, resulting altogether into a decreased reactivity. This favors the reduction of $\mathrm{CO}_{2}$ and less fuel is consumed. However, fewer hydrocarbons are then burned and more hydrocarbons appear in the exhaust. The dilution decreases also the peak temperature, allowing less $\mathrm{CO}$ to be converted into $\mathrm{CO}_{2}$. This means that dilution by EGR (if no thermal and chemical effects are considered) causes an increase of the hydrocarbon and CO emissions and decrease of $\mathrm{CO}_{2}$. 
Concerning the strength of the influence of the dilution, it can be calculated that the dilution decreases the $\mathrm{CO}_{2}$ emission by $40 \%$ having a dilution of only $10 \%$ at an equivalence ratio of 0.4 . To have the same effect at an equivalence ratio of 0.5 , the dilution needs to be increased up to $34 \%$. This results into an increase of hydrocarbon and $\mathrm{CO}$ emissions of respectively 250 and $75 \%$ ! Clearly, this is unacceptable. Inversely, a dilution of $10 \%$ at an equivalence ratio of 0.5 would decrease the hydrocarbon and $\mathrm{CO}$ emissions by respectively 28 and $11 \%$, while the $\mathrm{CO}_{2}$ emission would be decreased by only $6 \%$. At an intermediary equivalence ratio of 0.45 , it can be seen that a dilution of $10 \%$ would increase the hydrocarbon and CO emissions by respectively $27 \%$ and $15 \%$ and decrease the $\mathrm{CO}_{2}$ emission by $9 \%$. These results show that the dilution is perhaps not an ideal parameter to control the emissions of an HCCI engine, but rather a fixed dilution rate should be chosen where the initial values of the emissions are reasonable. Another parameter can then be used to control the emissions, such as the equivalence ratio. For instance, at an equivalence ratio of 0.42 and a dilution of $10 \%$, the hydrocarbon emission is 5000 ppmv, the $\mathrm{CO}$ emission is 0.175 vol\% and the $\mathrm{CO}_{2}$ emission is 4.7 vol\%. Increasing the equivalence ratio slightly to 0.44 makes the hydrocarbon emission drop to 3500 ppmv (-30\%) and the $\mathrm{CO}$ emission to 0.14 vol\% (-20\%), while the $\mathrm{CO}_{2}$ emission only increases to 5.2 vol\% (11\%). This makes the equivalence ratio an effective parameter for the emission control.

\subsection{Emissions from an HCCI engine with TRF's}

This section deals with the results regarding diesel and its surrogate (76 vol\% n-heptane and 24 vol\% toluene) and TRF's. Since aromatics present a great hazard to the environment and since diesel can contain different contents of aromatics, the influence of toluene in an n-heptane/toluene (representing different diesel surrogates) mixture on the emissions is also investigated in this subsection. Knowing that the diesel surrogate is in fact a TRF, its results are presented along with the results of the TRF's (indicated by a vertical line) in figures 12 to 15 .

The hydrocarbon emission that is observed in figure 9 increases, when increasing the toluene content in the fuel. Oxygen and $\mathrm{CO}$ show the same trend, while $\mathrm{CO}_{2}$ shows the opposite. Considering the assumption that diesel can be replaced by a diesel surrogate containing n-heptane and toluene, this suggests that the auto-ignition of diesels that contain more aromatics would result into emissions with higher hydrocarbon and CO amount. Aromatics are difficult

to auto-ignite as is the case for toluene. Toluene's mechanism has inhibiting reactions that reduce the $\mathrm{OH}$ radical content during the reactions. The overall reactivity becomes lower, less conversion takes place and consequently 
more hydrocarbons and oxygen are present in the exhaust gas. Moreover, it seems that $\mathrm{CO}$ is formed earlier in aromatic oxidation than in the oxidation of aliphatic species [23].

Concerning the values in figures 12 to 15 , it can be seen that the hydrocarbon emissions are more sensitive to the addition of toluene in the fuel than the emissions of $\mathrm{CO}$ and $\mathrm{CO}_{2}$. This can be seen by the steepness of the contour lines in figure 9 for the hydrocarbons. An example is taken at an equivalence ratio of 0.28. Comparing, for instance, n-heptane with a fuel containing 76 vol\% n-heptane and 24 vol\% toluene (the diesel surrogate), it can be seen that the addition of $24 \mathrm{vol} \%$ toluene results into an increase of the hydrocarbon emissions of $100 \%$, while the $\mathrm{CO}$ emissions increase by $50 \%$ and the $\mathrm{CO}_{2}$ emissions decrease by $9 \%$. At an equivalence ratio of 0.38 the results show an increase of $80 \%$ for the hydrocarbons, an increase of $15 \%$ for $\mathrm{CO}$ and a decrease of $10 \%$ for $\mathrm{CO}_{2}$. Theoretically, with respect to pure $n$-heptane, at an equivalence ratio of respectively 0.28 and 0.38 , the diesel surrogate should show an increase of $\mathrm{CO}_{2}$ concentration in the emission of about $3.5 \%$ for both equivalence ratios, using

$\left[\mathrm{CO}_{2}\right]_{\text {theoretical }}=\frac{a}{a+b / 2+d+e}=\frac{a}{a+b / 2+(a+0,25 b)(3,76 / \varphi)+(a+0,25 b)((1-\varphi) / \varphi)}$

with $a$ the average number of $\mathrm{C}$-atoms per molecule of fuel, $b$ the average number of $\mathrm{H}$-atoms per molecule in the fuel and $\varphi$ the equivalence ratio. The findings suggest that a higher aromatic content actually influences the combustion behavior reducing thereby, for diesel surrogates, the concentration of $\mathrm{CO}_{2}$ in the exhaust. The contour lines for oxygen have the same slope as those for the hydrocarbons. This suggests the good homogeneity of the fuel mixture with the air, since the slope in this type of maps indicates how the emission reacts to any changes in the parameters. Therefore, the same slope for oxygen and the hydrocarbons means that both react in a similar way to a change in the toluene content in the fuel and the equivalence ratio. This is the case if the contact between the oxygen molecules and the hydrocarbons are (almost) optimal, which is represented by the homogeneity of the mixture.

The emissions of diesel are presented in figure 16. It appears that diesel shows the same trends as the diesel surrogates. Since it was difficult to vaporize diesel enough so that its viscosity did not influence the auto-ignition process, not enough experiments could be made to present contour-maps. A temperature of $120{ }^{\circ} \mathrm{C}$ was needed for the diesel to by fully vaporized. In [14] it is found that without EGR (dilution in our case), during the HCCI combustion of diesel, the emission of $\mathrm{CO}$ was around 0.1 vol\%. These findings confirm the results obtained in figure 
16 with values between 0.07 and 0.14 vol\% depending on the equivalence ratio. Figure 16 also shows hydrocarbon emissions between 1500 and 1800 ppm for an engine speed of $600 \mathrm{rpm}$. These values are in the same range with the findings of [8], showing values between 900 and 1500 ppm for engine speeds between $1200 \mathrm{rpm}$ and $2400 \mathrm{rpm}$. All these values show that the emission of $\mathrm{CO}$ and hydrocarbons for HCCI combustion are still to be reduced. Nonetheless, it can be seen from figure 16 and especially from figures 4, 6, 8, 10, 12 and 14 that generally the emissions of $\mathrm{CO}$ and hydrocarbons can be reduced by either increasing the equivalence ratio or choosing the "right" fuel. Comparing the emissions of gasoline and diesel at no dilution and for the same equivalence ratio (0.39), it seems that the auto-ignition of diesel results into emissions containing a lower amount of hydrocarbons and CO than gasoline. Even if the operating conditions are not exactly the same, this comparison can be made if one wants to compare combustion modes with their corresponding fuels rather than the fuels alone, the former of which is of importance when considering the emission reduction. The difference that is observed between the auto-ignition of gasoline and diesel can be caused by the easiness of auto-ignition of diesel (once well evaporated) versus the difficulty of gasoline to auto-ignite. While some control parameters can reduce the emissions of $\mathrm{CO}$ and hydrocarbons, it has appeared that the emission of $\mathrm{CO}_{2}$ increases. A compromise has to be made, which needs a certain controlling strategy. An example follows proposing a certain strategy of controlling the emissions from an HCCI engine.

\section{An example of the outline of emission reduction control}

Regarding the results presented in figures 4 through 16, a useful aspect can be mentioned. These results can be used not only to propose a way of emission reduction, but also to investigate the possibility to control this emission reduction. For this purpose, figures 12,14 and 15 are re-discussed with the addition of figure 17 . The indicated efficiency is defined as the power output (by calculating the work done on the piston) divided by the power input (obtained from the amount of fuel injected and the lower heating value) multiplied by $100 \%$. Figures 12, 14, 15 and 17 allow showing the zones for which the parameters can be changed so that the emission is reduced as much as possible without reducing the indicated efficiency and without increasing the emission of $\mathrm{CO}_{2}$.

First of all it seems, from figure 17, that the indicated efficiency is very much influenced by the equivalence ratio. So this parameter has a narrower range for the control of the auto-ignition than the other parameters. The purpose is to have an equivalence ratio as low as possible for a low fuel consumption (being obviously also a function of the load), 
emissions that are as low as possible and an indicated efficiency as high as possible. From the results in the previous section, it seemed that a higher equivalence ratio is needed to have the same $\mathrm{CO}$ emissions for a fuel containing more toluene. The same goes for the hydrocarbon emissions. This implies that the fuel plays an important role on the choice of the equivalence ratio range and thus the control of the emission. The highest indicated efficiency is at an equivalence ratio of 0.32 at any fuel composition, the highest being for $40 \mathrm{vol} \%$ toluene. However, for this fuel composition, the emissions of $\mathrm{CO}$ and the hydrocarbons are at their highest for that equivalence ratio. The indicated efficiency is thus constantly in battle with the hydrocarbon and $\mathrm{CO}$ emissions. The slope of such a contour map represents certain sensitivity to a change in the parameter. It was seen that, for instance, the emissions of $\mathrm{CO}$ and $\mathrm{CO}_{2}$ are the least sensitive for a change in the fuel composition, compared to the hydrocarbon emission. This allows for reducing the hydrocarbon emission, without increasing too much the $\mathrm{CO}_{2}$ emission. An example is presented in figure 18 , for the same results.

Say, the engine operates at a certain fuel containing 40 vol\% of toluene in n-heptane at an inlet temperature of $70{ }^{\circ} \mathrm{C}$, a compression ratio of 10.2 and an equivalence ratio of 0.32 . Figure 18 shows that the engine operates then at an indicated efficiency of $38 \%$, having a $\mathrm{CO}_{2}$ emission of 3.7 vol\%, a $\mathrm{CO}$ emission of 0.35 vol\% and a hydrocarbon emission of 2450 ppmv. In order to reduce the hydrocarbon emission and CO emission, it seems necessary to reformulate the fuel so that it contains just $15 \mathrm{vol} \%$. In order not to increase the $\mathrm{CO}_{2}$ emission, the equivalence ratio is decreased to 0.305 . This is indicated by an arrow in figure 18 . In order to see what happens to the other results, the same arrow is transposed as dotted arrows. The dotted arrows show that the CO emission is reduced to 0.23 vol\%, the hydrocarbon emission to $1750 \mathrm{ppmv}$ and the indicated efficiency is decreased to about $35 \%$. It can be seen that in order to reduce the hydrocarbon and $\mathrm{CO}$ emissions, one loses some combustion efficiency. $\mathrm{The}^{\mathrm{CO}_{2}}$ emission is already low compared to conventional engines nowadays. However, if one wants to decrease even more the $\mathrm{CO}_{2}$ emission, it can be easily seen that the hydrocarbon and $\mathrm{CO}$ emissions will increase. Other configurations can be thought of, with other parameters. This example shows the complexity of controlling the emission reduction, which is translated as a competition between the reduction of various emissions and between the engine efficiency on one side and the emissions on the other. 


\section{Conclusions}

The effect that the dilution, fuel and the presence of toluene in the fuel has on the emissions of $\mathrm{NO}_{\mathrm{x}}, \mathrm{CO}, \mathrm{O}_{2}, \mathrm{CO}_{2}$ and hydrocarbons has been investigated for the case of the auto-ignition of gasoline, diesel and TRF's in an engine. No $\mathrm{NO}_{\mathrm{x}}$ has been measured. The dilution seemed to increase the emission of $\mathrm{CO}$ and hydrocarbons, while decreasing that of $\mathrm{CO}_{2}$. This follows from the decreased overall concentrations and kinetics that are caused by the dilution. The consequence is a decreased overall reactivity and especially a decreased peak temperature. The concentration of oxygen is also decreased, lowering the probability of a collision of oxygen with the fuel. Fewer hydrocarbons are then converted into $\mathrm{CO}_{2}$ and $\mathrm{H}_{2} \mathrm{O}$ and due to the lower temperature less $\mathrm{CO}$ is converted into $\mathrm{CO}_{2}$. It seemed that for the auto-ignition of gasoline, the dilution had a strong influence and should not be used as a parameter to control the emission. Instead, an optimal dilution value should be chosen, whereas another parameter as the equivalence ratio can be used for this emission control.

The content of toluene in the fuel appeared to have the same influence as the dilution but less pronouncedly. The effect appeared to be relatively strong for the hydrocarbon emissions, whereas the $\mathrm{CO}$ and $\mathrm{CO}_{2}$ emissions are affected less. This means that reducing the toluene content in an aliphatic hydrocarbon fuel would decrease the hydrocarbon emissions more than it would increase the $\mathrm{CO}_{2}$ emissions. This can be a useful result when formulating a fuel for HCCI applications. The results concerning the oxygen emission showed that the sensitivity of the oxygen to any changes in the addition of toluene or the equivalence ratio (represented by the slope in the corresponding contour map) was similar to that of the hydrocarbons. This suggests a good homogeneity of the fuel mixture and the air, indicating the advantage of the HCCI combustion mode.

Finally, it appeared that the auto-ignition of the diesel fuel resulted into a lower hydrocarbon and CO emission than gasoline. The explanation arises from the easiness of diesel to auto-ignite contrary to gasoline. The results suggest that both gasoline and diesel can be used in an HCCI engine, having possibilities to control their emissions. The difficulty, however, is to choose which parameter is most suitable for this control, which requires an extensive study. This work presented a part of such a study. Such an investigation could be facilitated by using a kinetic mechanism, containing species that are representative for gasoline and diesel. The emission of the gasoline surrogate showed good correspondence with that of gasoline. This suggests that a validated kinetic mechanism of a gasoline surrogate can be used for emission control of gasoline auto-ignition. The surrogate that is validated for gasoline is " 11 vol\% $\mathrm{n}$ heptane, $59 \mathrm{vol} \%$ iso-octane and 30 vol\% toluene". 
The results in this work can be used for purposes of emission reduction control. An example of this is presented in this paper, using the results from this work. 


\section{References}

1 Weiss M.A.; Heywood J.B.; Schafer A.; Natarajan V.K. Comparative Assessment of Fuel Cell Cars, Report MIT LFEE 2003-001 RP, Laboratory for Energy and the Environment, MIT, 2003. (http://lfee.mit.edu/publications)

2 Andrae J., Björnbom P., Cracknell R.F., Kalghatgi G.T. Autoignition of toluene reference fuels at high pressures modeled with detailed chemical kinetics. Combust. Flame 2007; 149: 2-24.

3 Machrafi H., Cavadias S. Three-stage autoignition of gasoline in an HCCI engine: An experimental and chemical kinetic modeling investigation. Combust. Flame 2008; 155: 557-570.

4 Corcione F.E., Costa M., Allocca L., Golovitchev V.I., Study of Multiple Injections and Auto-ignition of Diesel Sprays in a Constant Volume Vessel, COMODIA, The 6th Internat. Symp. on Diagnostics and Modeling of Combust. in Internal Combust. Engines (2004).

5 Huang Y., Sung C.J., Eng J.A. Dilution limits of n-butane/air mixtures under conditions relevant to HCCI combustion. Combust. Flame 2004; 136: 457-466.

6 Gauthier B.M., Davidson D.F., Hanson R.K. Shock tube determination of ignition delay times in full-blend and surrogate fuel mixtures. Combust. Flame 2004; 139: 300-311.

7 Aneja R., Bolton B., Hakim N., Pavlova-Mackinnon Z. Attaining Tier 2 Emissions Through Diesel Engine and Aftertreatment Integration - strategy and experimental results, $8^{\text {th }}$ Diesel Engine Emissions Reduction Conference - Detroit, 2001.

8 Garcia M.T., Espadafor Aguilar F.J.J., Lencero T.S. Experimental study of the performances of a modified diesel engine operating in homogeneous charge compression ignition (HCCI) combustion mode versus the original diesel combustion mode. Energy 2009; 34: 159-171.

9 Hatamura K. A Study on HCCI (Homogeneous Charge Compression Ignition) Gasoline Engine Supercharged by Exhaust Blow Down Pressure. SAE Technical Paper 2007-01-1873.

10 Hountalas D.T., Mavropoulos G.C., Binder K.B. Effect of exhaust gas recirculation (EGR) temperature for various EGR rates on heavy duty DI diesel engine performance and emissions. Energy 2008; 33:272-283.

11 Juttu S., Thipse S.S., Marathe N.V., Gajendra Babu M.K. Diesel HCCI Combustion Control Parameters Study Using n-Heptane-Reduced Chemical Kinetic Mechanism. SAE Technical Paper 2008-28-0036. 
12 Martinez-Frias J., Aceves S.M., Flowers D.L., Smith J.R., Dibble R.W. Equivalence Ratio-Egr Control of Hcci Engine Operation and the Potential for Transition to Spark-Ignited Operation. SAE Technical Paper 2001-01-3613.

13 Zeng W., Xie M. A novel approach to reduce hydrocarbon emissions from the HCCI engine. Chem. Eng. J. 2008; 139: 380-389.

14 Shi L., Cui Y., Deng K., Peng H., Chen Y. Study of low emission homogeneous charge compression ignition (HCCI) engine using combined internal and external exhaust gas recirculation (EGR). Energy 2006; $31: 2665-2676$.

15 Ganesh D., Nagarajan J. Homogeneous charge compression ignition (HCCI) combustion of diesel fuel with external mixture formation. Energy 2010; 35: 148-157.

16 Gillet B., Hardalupas Y., Kavounides C., Taylor A.M.K.P. Infrared absorption for measurement of hydrocarbon concentration in fuel/air mixtures (MAST-B-LIQUID). Appl. Therm. Eng. 2004; 24: 16331653.

17 Partridge Jr W.P., Laurendeau N.M. Nitric oxide formation by inverse diffusion flames in staged-air burners. Fuel 1995; 74: 1424-1430.

18 Schofield K. The enigmatic mechanism of the flame ionization detector: Its overlooked implications for fossil fuel combustion modelling. Progress Energ. Combust. Sc. 2008; 34: 330-350.

19 Holman JP. Experimental methods for engineers. NewYork: McGraw-Hill; 1994.

20 Daw C.S., Wagner R.M., Edwards K.D., Green Jr. J.B. Understanding the transition between conventional spark-ignited combustion and HCCI in a gasoline engine. Proc. Combust. Inst. 2007; 31: 2887-2894.

21 Lü X.-C., Chen W., Huang Z. A fundamental study on the control of the HCCI combustion and emissions by fuel design concept combined with controllable EGR. Part 1. The basic characteristics of HCCI combustion. Fuel 2005; 84: 1074-1083.

22 Lü X.-C., Chen W., Huang Z. A fundamental study on the control of the HCCI combustion and emissions by fuel design concept combined with controllable EGR. Part 2. Effect of operating conditions and EGR on HCCI combustion. Fuel 2005; 84: 1084-1092. Frank P., Herzler J., Just Th., Wahl C. High temperature reactions of phenyl oxidation. Proc. Combust. Inst. 1994; 25: 833-840. 


\section{Figure captions}

Figure 1: Experimental set-up

Figure 2: Indicated efficiencies as a function of the equivalence ratios for the fuels gasoline and TRF24 with an inlet temperature of $70{ }^{\circ} \mathrm{C}$ and a compression ratio of 10.2

Figure 3: Indicated mean effective pressures (IMEP) as a function of the equivalence ratios for the fuels gasoline and TRF24 with an inlet temperature of $70{ }^{\circ} \mathrm{C}$ and a compression ratio of 10.2

Figure 4: Iso-emissions of hydrocarbons (ppmv) at an inlet temperature of $70^{\circ} \mathrm{C}$, a compression ratio of 13.5 as a function of the dilution by $\mathrm{N}_{2}$ and the equivalence ratio for the fuel gasoline

Figure 5: Iso-emissions of oxygen (vol\%) at an inlet temperature of $70{ }^{\circ} \mathrm{C}$, a compression ratio of 13.5 as a function of the dilution by $\mathrm{N}_{2}$ and the equivalence ratio for the fuel gasoline

Figure 6: Iso-emissions of $\mathrm{CO}(\mathrm{vol} \%)$ at an inlet temperature of $70{ }^{\circ} \mathrm{C}$, a compression ratio of 13.5 as a function of the dilution by $\mathrm{N}_{2}$ and the equivalence ratio for the fuel gasoline

Figure 7: Iso-emissions of $\mathrm{CO}_{2}(\mathrm{vol} \%)$ at an inlet temperature of $70{ }^{\circ} \mathrm{C}$, a compression ratio of 13.5 as a function of the dilution by $\mathrm{N}_{2}$ and the equivalence ratio for the fuel gasoline

Figure 8: Iso-emissions of hydrocarbons (ppmv) at an inlet temperature of $70^{\circ} \mathrm{C}$, a compression ratio of 13.5 as a function of the dilution by $\mathrm{N}_{2}$ and the equivalence ratio for the surrogate of gasoline

Figure 9: Iso-emissions of oxygen (vol\%) at an inlet temperature of $70{ }^{\circ} \mathrm{C}$, a compression ratio of 13.5 as a function of the dilution by $\mathrm{N}_{2}$ and the equivalence ratio for the surrogate of gasoline

Figure 10: Iso-emissions of $\mathrm{CO}(\mathrm{vol} \%)$ at an inlet temperature of $70{ }^{\circ} \mathrm{C}$, a compression ratio of 13.5 as a function of the dilution by $\mathrm{N}_{2}$ and the equivalence ratio for the surrogate of gasoline

Figure 11: Iso-emissions of $\mathrm{CO}_{2}(\mathrm{vol} \%)$ at an inlet temperature of $70{ }^{\circ} \mathrm{C}$, a compression ratio of 13.5 as a function of the dilution by $\mathrm{N}_{2}$ and the equivalence ratio for the surrogate of gasoline

Figure 12: Iso-emissions of hydrocarbons (ppmv) at an inlet temperature of $70{ }^{\circ} \mathrm{C}$, a compression ratio of 10.2 and as a function of the toluene percentage in a $\mathrm{n}$-heptane/toluene mixture and the equivalence ratio

Figure 13: Iso-emissions of oxygen (vol\%) at an inlet temperature of $70{ }^{\circ} \mathrm{C}$, a compression ratio of 10.2 and as a function of the toluene percentage in a n-heptane/toluene mixture and the equivalence ratio

Figure 14: Iso-emissions of $\mathrm{CO}(\mathrm{vol} \%)$ at an inlet temperature of $70{ }^{\circ} \mathrm{C}$, a compression ratio of 10.2 and as a function of the toluene percentage in a n-heptane/toluene mixture and the equivalence ratio 
Figure 15: Iso-emissions of $\mathrm{CO}_{2}(\mathrm{vol} \%)$ at an inlet temperature of $70{ }^{\circ} \mathrm{C}$, a compression ratio of 10.2 and as a function of the toluene percentage in a n-heptane/toluene mixture and the equivalence ratio

Figure 16: Emissions of hydrocarbons, $\mathrm{CO}, \mathrm{CO}_{2}$ and oxygen at an inlet temperature of $120{ }^{\circ} \mathrm{C}$, a compression ratio of 10.2 as a function equivalence ratio, using the fuel diesel

Figure 17: Iso-indicated efficiencies (in \%) as a function of the equivalence ratio and the fuel composition of nheptane/toluene, for a compression ratio of 10,2 , an inlet temperature of $70^{\circ} \mathrm{C}$

Figure 18: Illustration of the emission control as a function of the equivalence ratio and the fuel composition of nheptane/toluene, for a compression ratio of 10,2 , an inlet temperature of $70^{\circ} \mathrm{C}$ 
Tables

Table 1: characteristics of the HCCI engine

\begin{tabular}{|c|c|c|c|}
\hline \multicolumn{2}{|c|}{ Engine geometry } & \multicolumn{2}{|c|}{ Valve timing } \\
\hline Compression ratio & $4-16$ & $\mathrm{EVO}$ & $140^{\circ} \mathrm{ATDC}$ \\
\hline Displacement volume & $612 \mathrm{~cm}^{3}$ & EVC & $15^{\circ}$ ATDC \\
\hline Bore $\mathrm{x}$ stroke & $82.55 \times 114.5 \mathrm{~mm}$ & IVO & $10^{\circ} \mathrm{ATDC}$ \\
\hline Connecting rod to the crank radius ratio & 4.44 & IVC & $146^{\circ} \mathrm{BTDC}$ \\
\hline
\end{tabular}


Table 2: Experimental conditions

\begin{tabular}{|c|c|c|c|c|c|}
\hline Fuel & Gasoline & $\begin{array}{l}\text { Gasoline } \\
\text { surrogate }\end{array}$ & Diesel & TRF's & Diesel surrogate \\
\hline Compression ratio [-] & 13.5 & 13.5 & 10.2 & 10.2 & 10.2 \\
\hline Inlet temperature $\left[{ }^{\circ} \mathrm{C}\right]$ & 70 & 70 & 120 & 70 & 70 \\
\hline Equivalence ratio [-] & $0.39-0.53$ & $0.39-0.53$ & $0.33-0.54$ & $0.26-0.39$ & $0.26-0.39$ \\
\hline $\begin{array}{lll}\text { Dilution by } & \mathrm{N}_{2} \\
\text { [vol\%] } & & \\
\end{array}$ & $0-37$ & $0-37$ & --- & --- & --- \\
\hline
\end{tabular}


Table 3: Measurement accuracies

\begin{tabular}{lll}
\hline & Measurement range & Accuracy \\
\hline Fuel flow (ml/min) & $0.0-10.0$ & 0.05 \\
Air flow (1/min) & $0-200$ & 1 \\
EGR flow (l/min) & $0-200$ & 1 \\
Inlet temperature $\left({ }^{\circ} \mathrm{C}\right)$ & $10-200$ & 1 \\
EGR temperature $\left({ }^{\circ} \mathrm{C}\right)$ & $10-200$ & 1 \\
Injection pressure (bar) & $0-3$ & 0.05 \\
Cylinder pressure (bar) & $1-100$ & 1 \\
Inlet pressure (bar) & $1-3$ & 0.03 \\
$\mathrm{CO}^{(\text {vol } \%)}$ & $0.1-10$ & $2 \%$ \\
$\mathrm{CO}_{2}$ (vol\%) & $0.1-50$ & $2 \%$ \\
$\mathrm{O}_{2}$ (vol\%) & $1-25$ & $2 \%$ \\
$\mathrm{NO}_{\mathrm{x}}$ (ppmv) & $10-1000$ & $2 \%$ \\
$\mathrm{Hydrocarbons}(\mathrm{ppmv})$ & $100-10000$ & $2 \%$
\end{tabular}




\section{Figures}

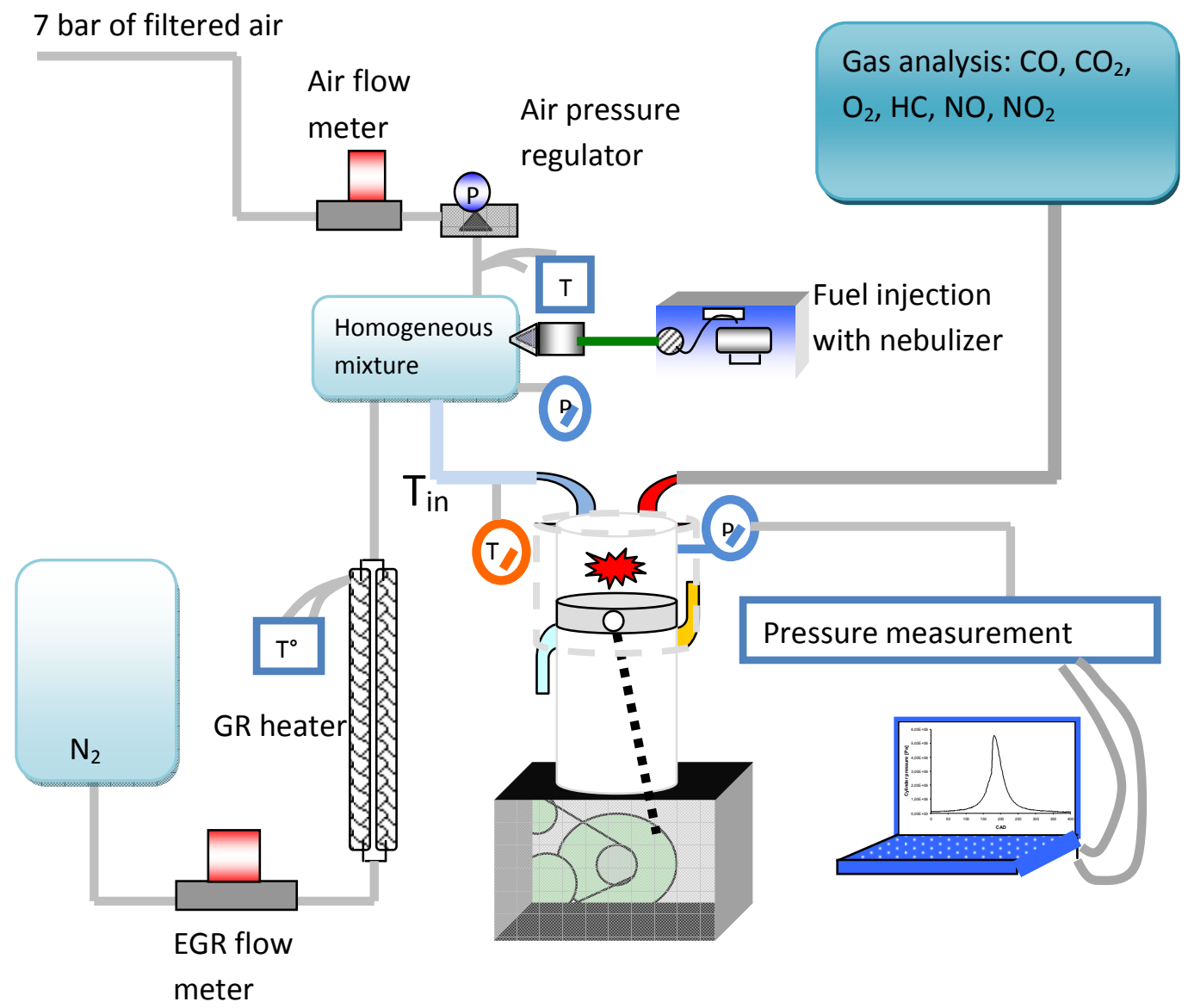

Figure 1: Experimental set-up 


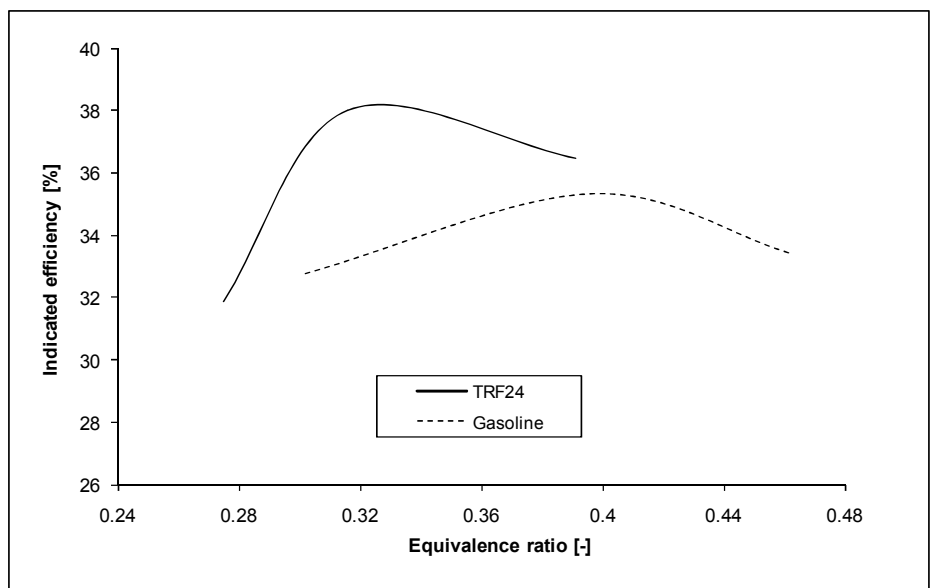

Figure 2: Indicated efficiencies as a function of the equivalence ratios for the fuels gasoline and TRF24 with an inlet temperature of $70^{\circ} \mathrm{C}$ and a compression ratio of 10.2 


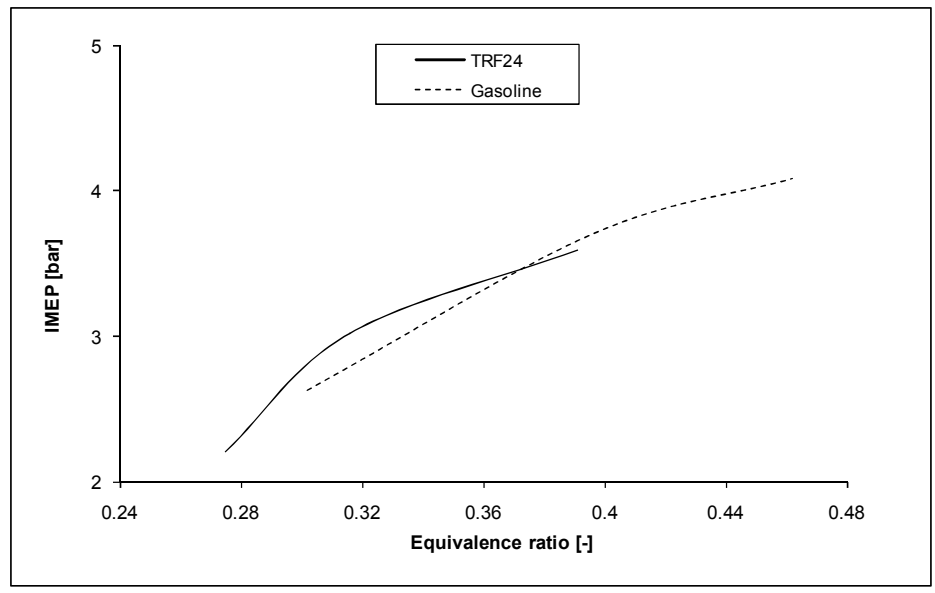

Figure 3: Indicated mean effective pressures (IMEP) as a function of the equivalence ratios for the fuels gasoline and TRF24 with an inlet temperature of $70^{\circ} \mathrm{C}$ and a compression ratio of 10.2 


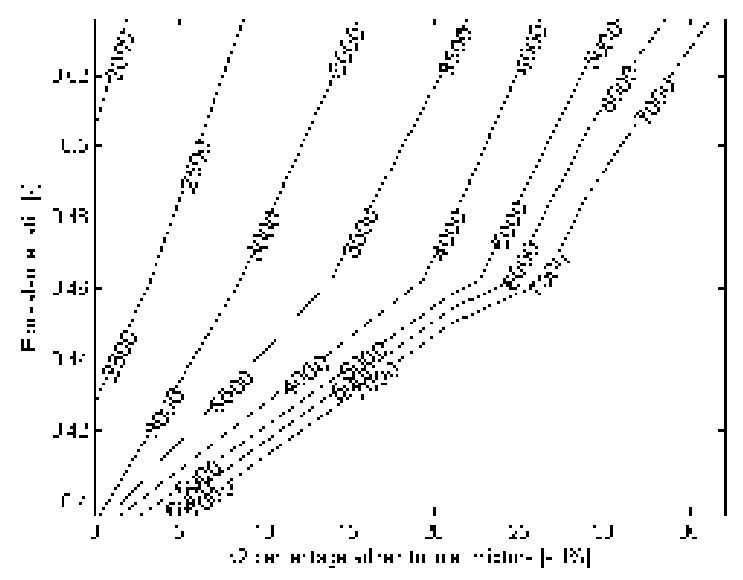

Figure 4: Iso-emissions of hydrocarbons (ppmv) at an inlet temperature of $70{ }^{\circ} \mathrm{C}$, a compression ratio of 13.5 as a function of the dilution by $\mathrm{N}_{2}$ and the equivalence ratio for the fuel gasoline 


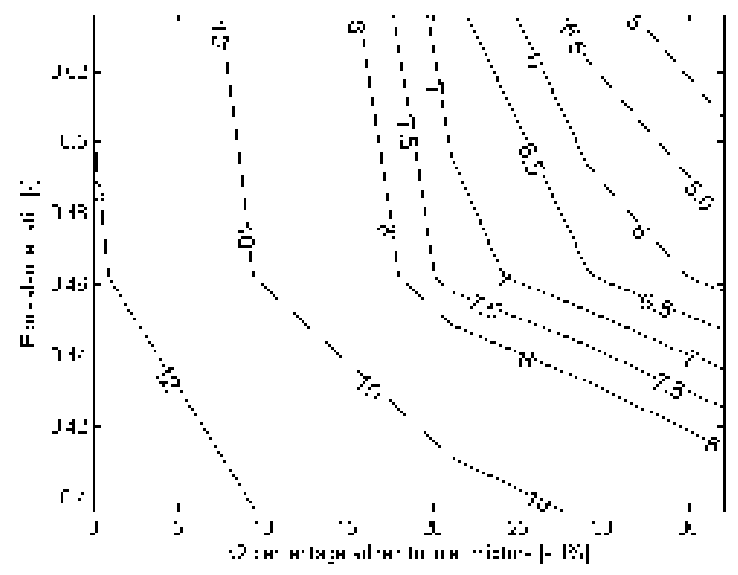

Figure 5: Iso-emissions of oxygen (vol\%) at an inlet temperature of $70{ }^{\circ} \mathrm{C}$, a compression ratio of 13.5 as a function of the dilution by $\mathrm{N}_{2}$ and the equivalence ratio for the fuel gasoline 


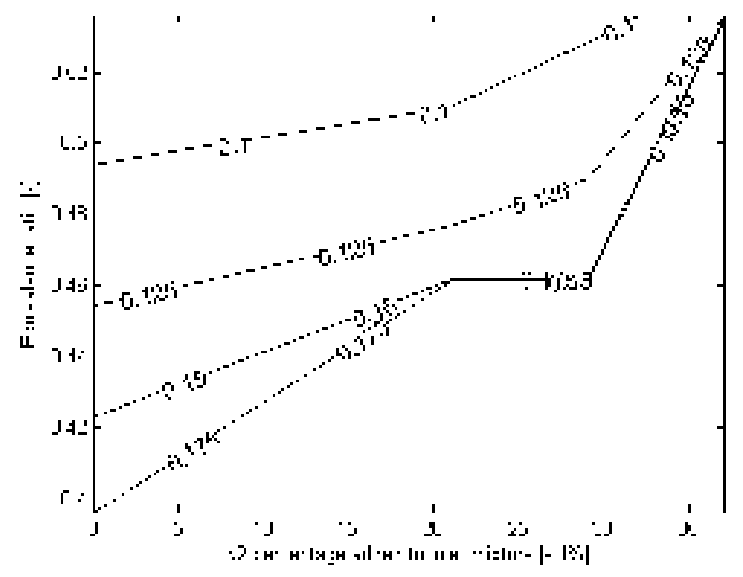

Figure 6: Iso-emissions of $\mathrm{CO}$ (vol\%) at an inlet temperature of $70^{\circ} \mathrm{C}$, a compression ratio of 13.5 as a function of the dilution by $\mathrm{N}_{2}$ and the equivalence ratio for the fuel gasoline 


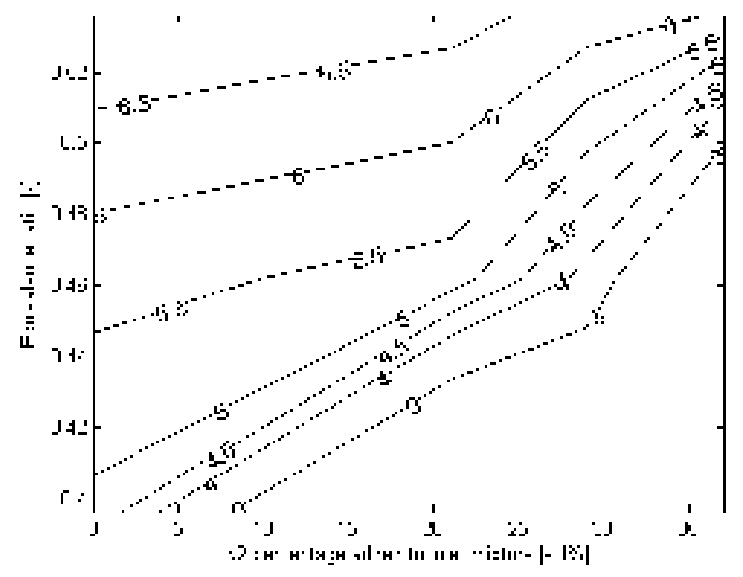

Figure 7: Iso-emissions $\mathrm{CO}_{2}\left(\right.$ vol\%) at an inlet temperature of $70^{\circ} \mathrm{C}$, a compression ratio of 13.5 as a function of the dilution by $\mathrm{N}_{2}$ and the equivalence ratio for the fuel gasoline 


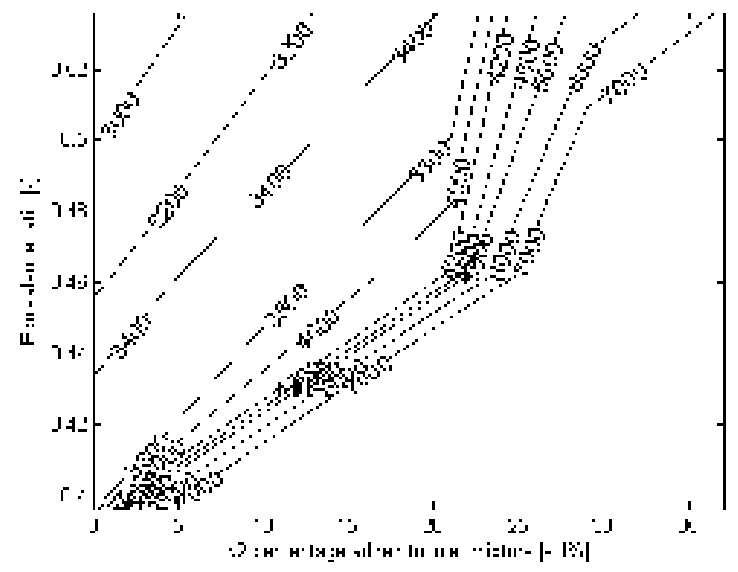

Figure 8: Iso-emissions of hydrocarbons (ppmv) at an inlet temperature of $70^{\circ} \mathrm{C}$, a compression ratio of 13.5 as a function of the dilution by $\mathrm{N}_{2}$ and the equivalence ratio for the surrogate of gasoline 


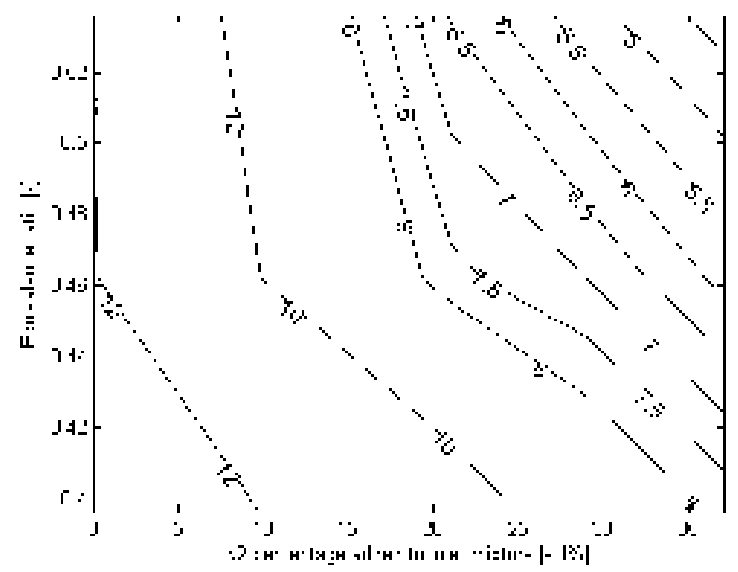

Figure 9: Iso-emissions of oxygen (vol\%) at an inlet temperature of $70^{\circ} \mathrm{C}$, a compression ratio of 13.5 as a function of the dilution by $\mathrm{N}_{2}$ and the equivalence ratio for the surrogate of gasoline 


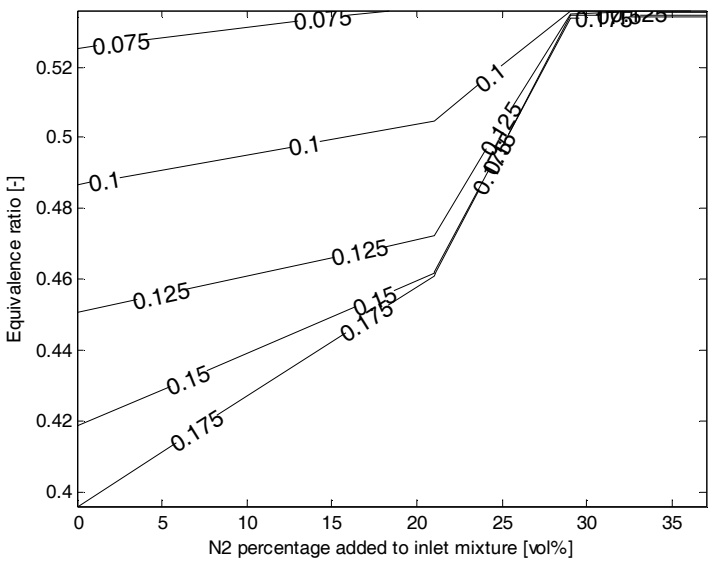

Figure 10: Iso-emissions of $\mathrm{CO}(\mathrm{vol} \%)$ at an inlet temperature of $70^{\circ} \mathrm{C}$, a compression ratio of 13.5 as a function of the dilution by $\mathrm{N}_{2}$ and the equivalence ratio for the surrogate of gasoline 


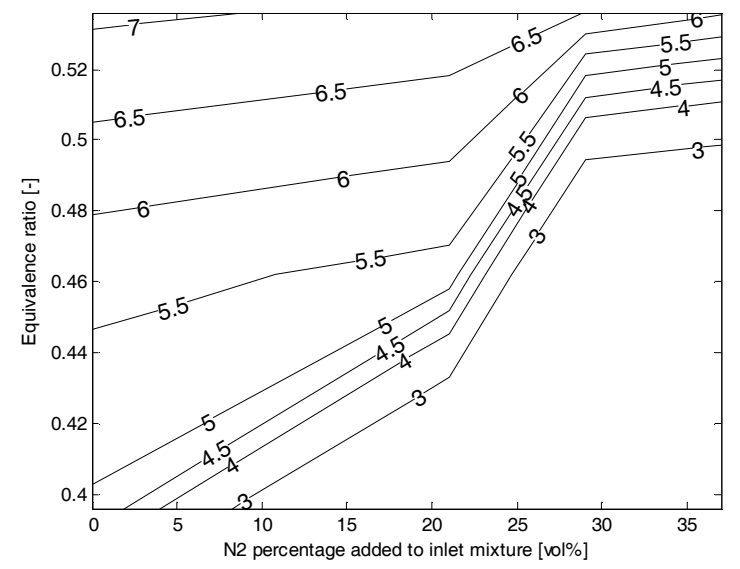

Figure 11: Iso-emissions of $\mathrm{CO}_{2}(\mathrm{vol} \%)$ at an inlet temperature of $70^{\circ} \mathrm{C}$, a compression ratio of 13.5 as a function of the dilution by $\mathrm{N}_{2}$ and the equivalence ratio for the surrogate of gasoline 


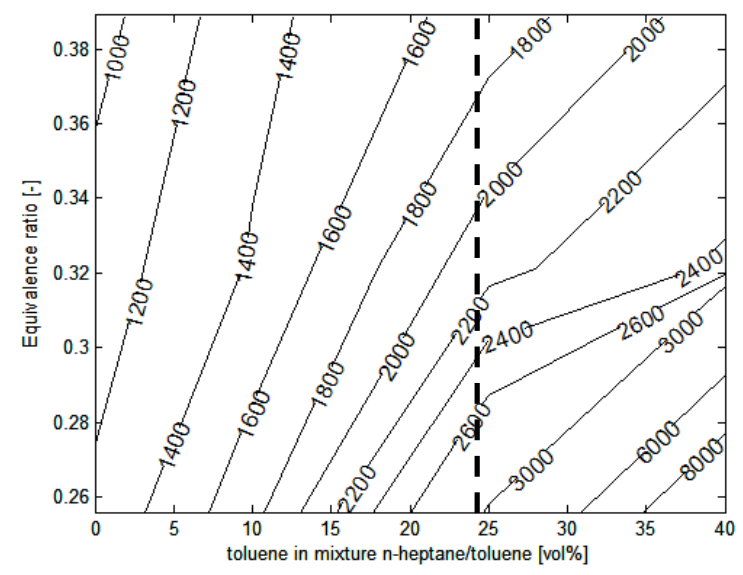

Figure 12: Iso-emissions of hydrocarbons (ppmv) at an inlet temperature of $70{ }^{\circ} \mathrm{C}$, a compression ratio of 10.2 and as a function of the toluene percentage in a n-heptane/toluene mixture and the equivalence ratio 


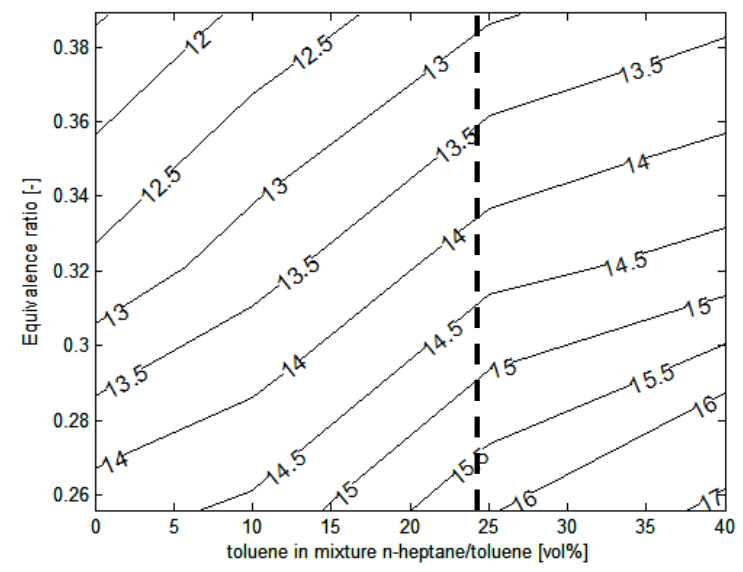

Figure 13: Iso-emissions of oxygen (vol\%) at an inlet temperature of $70^{\circ} \mathrm{C}$, a compression ratio of 10.2 and as a function of the toluene percentage in a n-heptane/toluene mixture and the equivalence ratio 


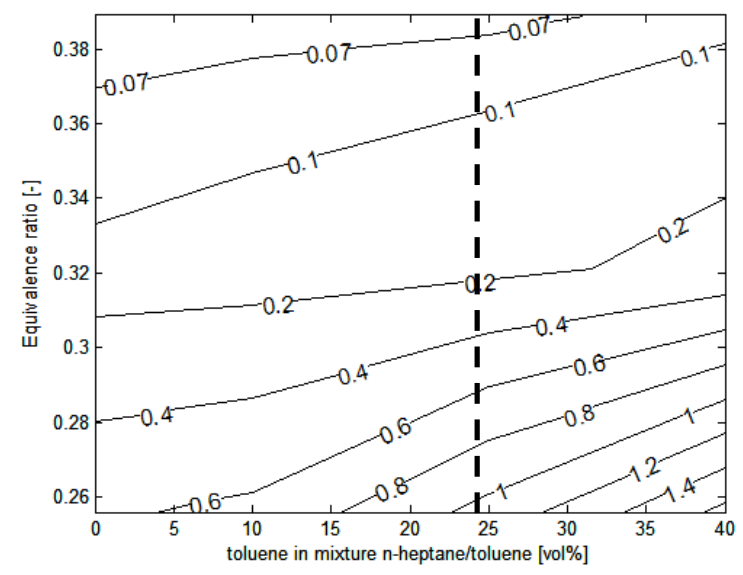

Figure 14: Iso-emissions of $\mathrm{CO}$ (vol\%) at an inlet temperature of $70{ }^{\circ} \mathrm{C}$, a compression ratio of 10.2 and as a function of the toluene percentage in a n-heptane/toluene mixture and the equivalence ratio 


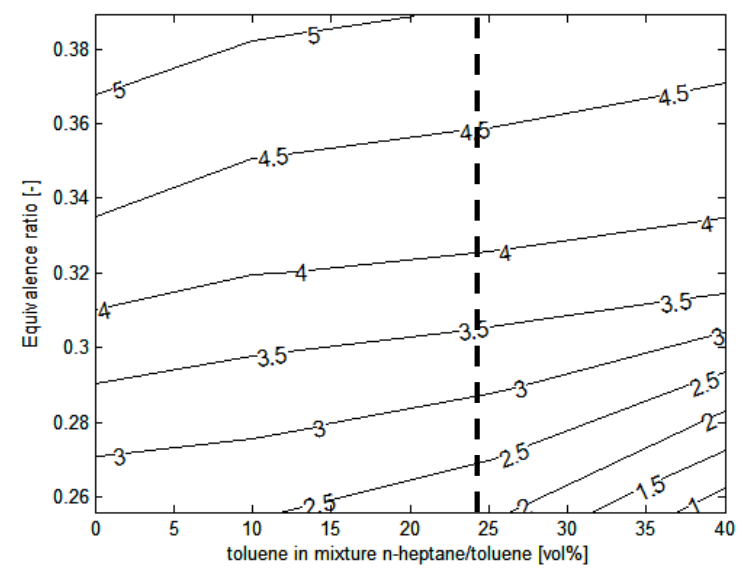

Figure 15: Iso-emissions of $\mathrm{CO}_{2}(\mathrm{vol} \%)$ at an inlet temperature of $70{ }^{\circ} \mathrm{C}$, a compression ratio of 10.2 and as a function of the toluene percentage in a n-heptane/toluene mixture and the equivalence ratio 


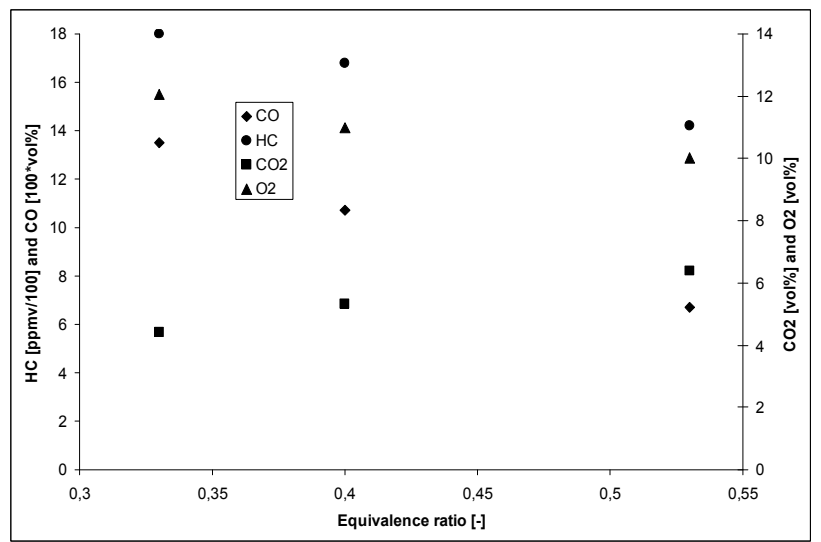

Figure 16: Emissions of hydrocarbons, $\mathrm{CO}, \mathrm{CO}_{2}$ and oxygen at an inlet temperature of $120{ }^{\circ} \mathrm{C}$, a compression ratio of 10.2 as a function equivalence ratio, using the fuel diesel 


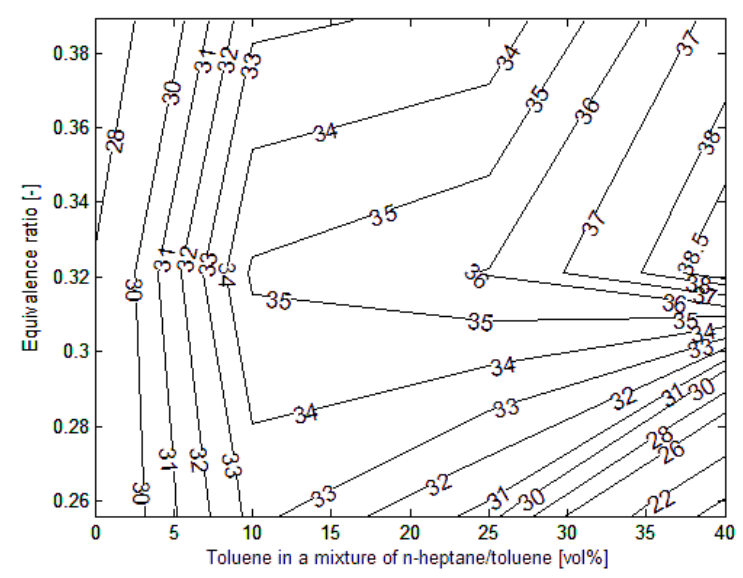

Figure 17: Iso-indicated efficiencies (in \%) as a function of the equivalence ratio and the fuel composition of $n$ heptane/toluene, for a compression ratio of 10,2, an inlet temperature of $70^{\circ} \mathrm{C}$ 


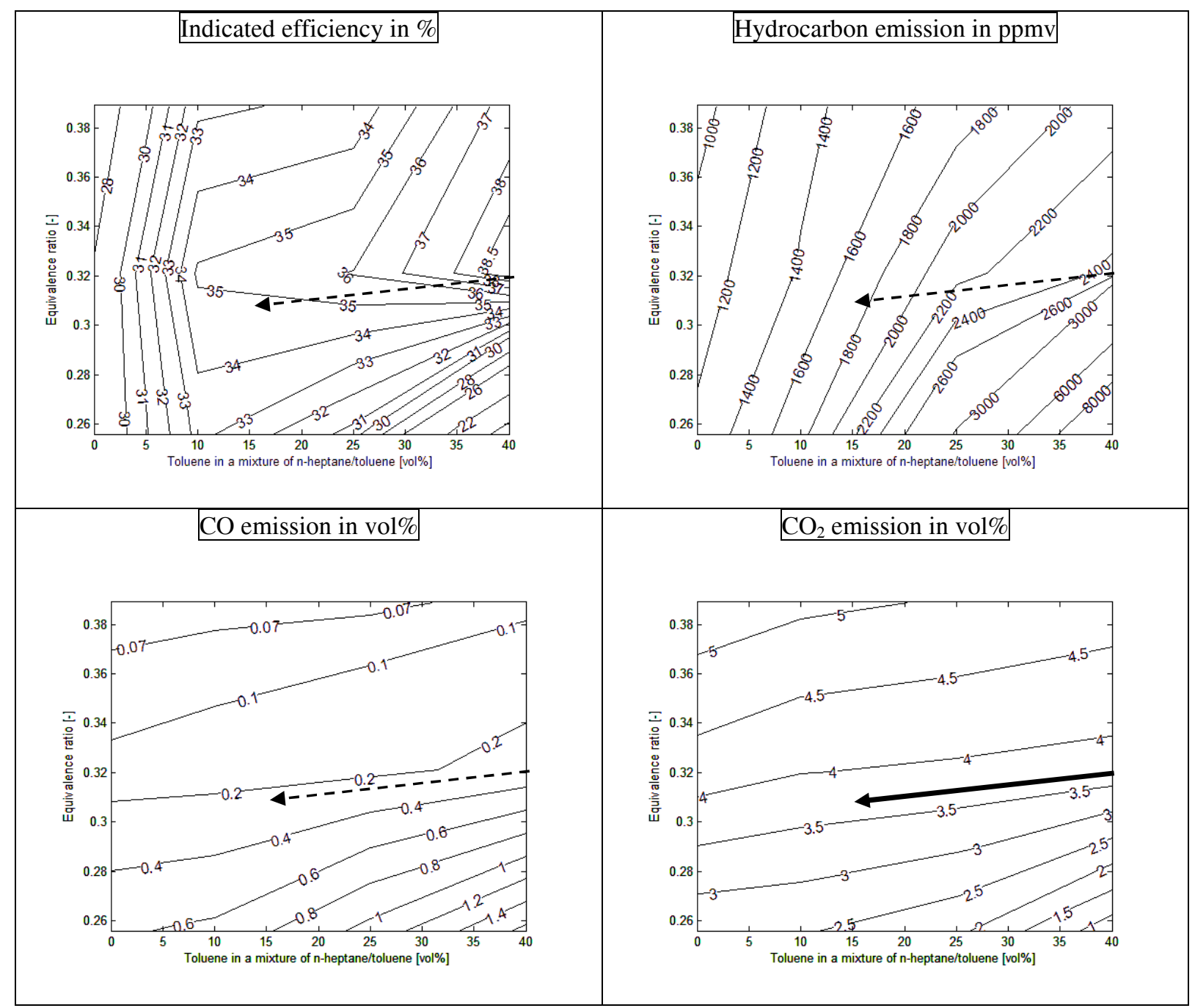

Figure 18: Illustration of the emission control as a function of the equivalence ratio and the fuel composition of $n$ heptane/toluene, for a compression ratio of 10,2 , an inlet temperature of $70^{\circ} \mathrm{C}$ 